\title{
BMJ Open New graduate doctors' preparedness for practice: a multistakeholder, multicentre narrative study
}

\author{
Lynn V Monrouxe, ${ }^{1}$ Alison Bullock, ${ }^{2}$ Gerard Gormley, ${ }^{3}$ Kathrin Kaufhold, ${ }^{4}$ \\ Narcie Kelly, ${ }^{5}$ Camille Emilie Roberts, ${ }^{6}$ Karen Mattick, ${ }^{7}$ Charlotte Rees ${ }^{8}$
}

To cite: Monrouxe LV, Bullock A, Gormley G, et al. New graduate doctors preparedness for practice: a multistakeholder, multicentre narrative study. BMJ Open 2018;8:e023146. doi:10.1136/ bmjopen-2018-023146

- Prepublication history for this paper is available online. To view, these files please visit the journal online (http://dx.doi org/10.1136/bmjopen-2017023146).

Received 30 March 2018 Revised 4 June 2018 Accepted 17 July 2018

Check for updates

(c) Author(s) (or their employer(s)) 2018. Re-use permitted under CC BY-NC. No commercial re-use. See rights and permissions. Published by BMJ.

For numbered affiliations see end of article.

Correspondence to

Professor Lynn V Monrouxe;

monrouxe@me.com

\section{ABSTRACT}

Objective While previous studies have begun to explore newly graduated junior doctors' preparedness for practice, findings are largely based on simplistic survey data or perceptions of newly graduated junior doctors and their clinical supervisors alone. This study explores, in a deeper manner, multiple stakeholders' conceptualisations of what it means to be prepared for practice and their perceptions about newly graduated junior doctors' preparedness (or unpreparedness) using innovative qualitative methods.

Design A multistakeholder, multicentre qualitative study including narrative interviews and longitudinal audio diaries.

Setting Four UK settings: England, Northern Ireland, Scotland and Wales.

Participants Eight stakeholder groups comprising $n=185$ participants engaged in 101 narrative interviews (27 group and 84 individual). Twenty-six junior doctors in their first year postgraduation also provided audio diaries over a 3-month period.

Results We identified 2186 narratives across all participants (506 classified as 'prepared', 663 as 'unprepared', 951 as 'general'). Seven themes were identified; this paper focuses on two themes pertinent to our research questions: (1) explicit conceptualisations of preparedness for practice; and (2) newly graduated junior doctors' preparedness for the General Medical Council's (GMC) outcomes for graduates. Stakeholders' conceptualisations of preparedness for practice included short-term (hitting the ground running) and long-term preparedness, alongside being prepared for practical and emotional aspects. Stakeholders' perceptions of medical graduates' preparedness for practice varied across different GMC outcomes for graduates (eg, Doctor as Scholar and Scientist, as Practitioner, as Professional) and across stakeholders (eg, newly graduated doctors sometimes perceived themselves as prepared but others did not).

Conclusion Our narrative findings highlight the complexities and nuances surrounding new medical graduates' preparedness for practice. We encourage stakeholders to develop a shared understanding (and realistic expectations) of new medical graduates' preparedness. We invite medical school leaders to increase the proportion of time that medical students spend participating meaningfully in multiprofessional teams during workplace learning.

\section{Strengths and limitations of this study}

This is the first study to explore multiple stakeholders' perceptions of recent medical graduates' preparedness for practice including under-represented groups such as patient and public representatives and policy and government officials.

- Our use of narrative interviewing and longitudinal audio diaries has enabled us to capture narratives of preparedness for practice temporally close to those experiences.

- We collected large amounts of data from stakeholders based in all four UK countries, enhancing the transferability of our study findings.

- Mapping preparedness to the General Medical Council's (GMC) outcomes for graduates enables the focus of future research and interventions to target those areas where graduates are 'underprepared'.

- Given the participant-led nature of our data collection methods, we were only able to collect a partial picture of preparedness for practice for all GMC outcomes.

\section{INTRODUCTION}

Everyone stands to benefit from medical graduates who are well prepared to start work as junior doctors. However, ensuring that those graduates are prepared for the complexity, and pressures, of today's practice is more challenging than ever. First, as the healthcare needs of modern society are changing, ${ }^{12}$ the goal of preparedness constantly changes too. Second, our collective understanding of approaches to preventing, diagnosing and managing diseases is also developing. ${ }^{3}$ This in turn demands changes to established medical practice, new structures for healthcare delivery and novel approaches to medical education and training. ${ }^{5-7}$ There are different expectations and opportunities for new medical graduates today compared with previous generations. ${ }^{68}$ Finally, there is a lack of clarity about the task of preparing medical graduates for practice; an important yet thorny question is "preparedness for what 
exactly?'. ${ }^{10}$ There is a difference between preparing graduates for immediate practice, and preparing them for careers in medicine across a wide range of specialities in an ever-changing healthcare environment. The urgent need for research and development in the area of newly graduated doctors' preparedness is highlighted, for example, by studies reporting increased incidences of adverse patient outcomes over the time period when new graduates start work as junior doctors. ${ }^{11}{ }^{12}$ Indeed, major challenges and impact on patient care exist, resulting from financial and staffing pressures, and the associated risk of burnout for newly graduated junior doctors. ${ }^{13}$ Improving new graduate doctors' preparedness for practice is therefore likely to have a tangible positive impact on patient outcomes.

Despite significant investment in medical education in the UK over recent years, a report published in 2014 found that only $70 \%$ of new graduate doctors felt they were well prepared for their first doctor role. ${ }^{14}$ Importantly, clinical supervisors also feel that new graduate doctors are not always well prepared for their roles and report their concerns that patient care and safety may be negatively affected when they initially start work. ${ }^{15}$ Arguably, new graduate doctors will never feel fully prepared for starting clinical practice. Indeed, given the complex and unpredictable nature of clinical care, undue confidence prior to gaining direct experience might seem inappropriate. There are numerous studies published about medical graduates' preparedness for practice, most of which are quantitative retrospective cross-sectional surveys of graduate perceptions, ${ }^{16-19}$ with fewer studies employing qualitative or longitudinal approaches and exploring the perceptions of other stakeholders about graduate preparedness such as clinical supervisors. ${ }^{20}$ A recent rapid review of the literature about preparedness for practice of UK medical graduates, ${ }^{10}$ found that very few studies defined preparedness for practice and that the evidence was mixed in terms of many aspects of preparedness. There were marked variations across this literature in terms of perceptions of preparedness from one trainee to the next, within trainees across time and across research tools in terms of what new medical graduates report feeling prepared for (or not).$^{10}$ Importantly, the rapid review flagged further limitations with the existing literature (eg, focus on short-term preparedness, and reliance on self-report of recently graduated doctors only) and recommended multisite and longitudinal research designs using a range of research methods: 'to understand the concept and process of preparedness alongside the variety of individual, cultural and organisational issues that might impact on this'. ${ }^{10}$

According to Eva and Regehr, a range of factors can affect individuals' self-reports: individuals' beliefs in their own abilities to complete tasks (self-efficacy); their abilities to draw context-free general conclusions about their own skills or knowledge in specific domains (self-concept); individuals' access to their own knowledge (meta-cognition); the various heuristics and 'short-cuts' in thinking that individuals use (cognition); their pattern-recognition and fact-checking (models of expert performance) and reflective practice. ${ }^{21}$ The implication from this work is that, in isolation, quantitative self-report measures of 'preparedness in general' are unlikely to be a meaningful and useful construct of whether newly graduated doctors are actually prepared for practice. Eva and Regehr, ${ }^{21}$ drawing on Schön, ${ }^{22}$ also make the distinction between 'reflection-on-practice' and 'reflection-in-practice'. Importantly, Eva and Regehr assert that 'reflection-on-practice' is more accurate when considering specific events (rather than generalised events), when one reflects on a situation regarding a particular patient than when rating 'one's own strengths and weaknesses in an acontextual manner' (p. S53). Given the reliance of the majority of previous research on simplistic data, and the lack of multisite and longitudinal study designs, ${ }^{10}$ this study presents a large multistakeholder, multicentre narrative interview and audio diary study, which aimed to understand the extent to which current UK medical graduates are prepared for practice. To the best of our knowledge, this is the largest study of its kind and provides uniquely rich and contextualised insights into medical graduates' preparedness for practice in the UK.

\section{Aims and research questions}

We aim to explore issues around preparedness for practice in terms of how the concept is understood across a range of stakeholder groups and to understand aspects in which new medical graduates are deemed prepared (or unprepared) for clinical practice with the following two broad research questions (RQ):

- RQ1: How do stakeholders conceptualise "preparedness for practice'?

- RQ2: To what extent do various stakeholders perceive recent medical graduates to be prepared for practice, and what factors do they attribute to this?

\section{METHODS \\ Design}

A qualitative narrative interview and longitudinal audio diary design was used. Narrative interviewing was employed as it provides an opportunity for participants to ground their contributions in actual lived experiences. ${ }^{23}$ Thus, narratives begin to overcome the acontextual nature of event reporting that presently prevails in the literature. ${ }^{21}$ Furthermore, audio diaries, which were recorded by the newly graduated doctors, provided them with an opportunity to select and narrate ongoing events close to the time of those events, and in the privacy of their own space. Longitudinal audio diaries therefore facilitated participants' remembering and the conveying of their feelings during those events. ${ }^{24}$

\section{Patient and public involvement}

A group of six patient and public representatives (PPRs) were consulted prior to the design of the study to ask their opinions on how to include patients and their families in 
the study (eg, recruitment, best data collection methods, etc). Dr Philip Bell was appointed the PPR for the study by the group. Prior to data collection, Dr Bell was interviewed by two researchers (KK and CEK) using the interview protocol designed by the wider team. Through this interview, he advised on changes in terminology and the focus of questions to enable us to develop the interview protocol specifically for the PPR groups. Due to the nature of his interview (being focused on the design of the protocol), we did not use this interview in the final analysis. Patients' involvement in the recruitment of other patient participants took the form of snowballing (a recruitment method whereby participants invite their peers to join them in the study). All PPR participants were given a copy of the final report which was sent to the GMC who funded the programme of research.

\section{Participants}

Eight stakeholder groups comprising $\mathrm{n}=185$ individuals participated in the interviews. The largest group comprised newly graduated doctors: $\mathrm{n}=34$ postgraduate year 1 doctors (PGY1s, we use this terminology as it is internationally recognised); these comprised newly graduated (approximately 4 months) junior doctors and $\mathrm{n}=23$ postgraduate year 2 doctors (PGY2s). In the UK junior doctors obtain full registration with the GMC at the end of their PGY1 year. Other stakeholder groups comprised: $\mathrm{n}=32$ clinical educators (CEs); $\mathrm{n}=30$ deans and training programme leads (DTPLs); $\mathrm{n}=13$ healthcare professionals (HCPs: eg, nurses, pharmacists, etc); $\mathrm{n}=7$ employers (EMPs); $\mathrm{n}=25$ PPRs and $\mathrm{n}=11$ policy and government officials (POLs).

PGY1 and PGY2 doctors were mainly aged between 25 and 34 years $(74 \%)$ and $62 \%$ were female. The healthcare stakeholders (CE, DTPL, HCP and EMP) were mainly aged between 30 and 59 years $(79 \%)$ with $42 \%$ female. The PPRs were mainly $60+$ years $(72 \%)$ and $68 \%$ female. Twenty-six PGY1s recorded audio-diaries for an average of 3 months: all aged 25-29 years, 50\% female and 77\% direct-entry undergraduates. Additionally, 19/26 participated in an exit interview.

\section{Data collection}

Twenty-seven group and 84 individual interviews were held (total 94 hours 30 min data: mean interview duration $56 \mathrm{~min}$ ). Additionally, 254 discrete audio diary entries were submitted from the 26 PGY1 participants (comprising 18 hours 9 min; mean $4 \mathrm{~min} 30 \mathrm{~s}$ per audio diary; range $32 \mathrm{~s}-13 \mathrm{~min} 13 \mathrm{~s})$. Furthermore, we held four group and seven individual exit interviews with 19/26 PGYls (total 7 hours $48 \mathrm{~min}$, mean $43 \mathrm{~min}$ ). Taking advice from our reference group (see 'Acknowledgements' section), we employed multiple methods of recruitment including: email; notices on notice-boards; snowballing and face-toface recruitment during formal curricula. Information sheets and consent forms were sent to prospective participants. PGY1s were asked to 'opt-into' the audio diary phase during interview sessions. Interviews were conducted in a quiet room at participants' convenience. One participant had her carer with her, who remained silent during the interview. Five researchers (KK, GS, JC, NK, CEK: see 'Acknowledgements' section) conducted the interviews across the four UK settings, all of whom were trained together for the narrative interviewing process prior to data collection. One researcher (CJ: see 'Acknowledgements' section) led the audio diary data collection. The interviews all began with an orienting question: what does the phrase 'preparedness for practice' mean to you? Next, we asked participants: 'how prepared are you for practice?' or 'how prepared do you think medical graduates are for practice?', employing narrative interviewing techniques to elicit stories from participants about specific events of their own or involving new medical graduates' preparedness for practice. For the audio diaries, we sensitised participants to the following prompt: 'please tell us of a time since you last spoke with us when you felt prepared for practice and also a time when you felt less prepared', in order to collect narratives of preparedness over the 3-month data collection period.

\section{Data analysis}

The data were transcribed and the audios and transcriptions were managed via Atlas.ti. ${ }^{25}$ The thematic Framework Analysis method was used comprising: (1) familiarisation, (2) identifying a coding framework, (3) coding, (4) charting and (5) mapping and interpretation ${ }^{26}$ :

1. Familiarisation: 10 researchers (LVM, CER, AB, KM, JC, CJ, KK, CEK, NK and GS) and two clinical consultants (see 'Acknowledgements' section) each read a transcript from an interview (either focus group or individual interview) across the different participant groups and up to three audio diary transcripts with PGY1 doctors, with each transcript being read by at least two researchers.

2. Development of coding framework: a series of face-to-face and video-conference meetings were held across 2 days with researchers discussing themes identified inductively from the data. An existing coding framework (developed via a rapid review of the literature $)^{10}$ was then mapped onto the inductive framework (by LVM), ensuring that all outcomes for UK medical graduates, and preparedness themes and subthemes previously identified, were included as 'potential codes'. A coding framework outlining all themes, subthemes, definitions and illustrative quotes, alongside coding instructions, was produced to facilitate coding consistency by multiple coders.

3. Coding: KK led the coding with additional work by CEK, $\mathrm{CJ}$ and LVM. The coders met regularly to discuss developments and provide feedback on one another's coding decisions. LVM double-checked a subset of coding for consistency. The unit of analysis was the narratives of personal experience with narratives being coded to the themes and subthemes they addressed and the level of preparedness narrated by the participant (if any). However, many narratives were complex with el- 
ements of both preparedness and unpreparedness. We therefore classified the narratives according to how the narrators constructed the events (eg, explicitly saying something such as "a time when I felt prepared..."). Further coding of additional information, such as context (eg, where the event occurred) and facilitating/ inhibiting factors was also undertaken.

4. Charting: the data were managed in Atlas.ti ${ }^{25}$ to facilitate retrieval by theme/subtheme and participant group, enabling us to analyse similarities and differences across the data.

5. Mapping and interpretation: LVM managed the data retrieval, mapping themes across participant groups and developing initial interpretations. These were developed further by CER, KM, GJG, AB and KK and discussed in light of existing literature and theory.

\section{RESULTS}

We identified $n=2186$ narratives across all participants, of which $\mathrm{n}=506$ were classified as 'prepared', $\mathrm{n}=663$ as 'unprepared' and $\mathrm{n}=951$ as 'general' (general events were not commented on in terms of preparedness).

Seven main themes were identified in the wider study: (1) explicit conceptualisations of preparedness for practice; (2) medical graduates' preparedness for GMC outcomes for graduates; (3) medical graduates' preparedness for non-GMC outcomes; (4) transitions and transition interventions; (5) medical school experiences and preparedness; (6) inhibiting and facilitating factors of medical graduates' preparedness and (7) bringing full registration forward.

In this paper, we report the findings of themes 1 and 2 , with the remaining themes and analyses presented elsewhere. ${ }^{927-30}$ Note that we provide excerpts in accompanying boxes to illustrate our findings (participants' unique identifiers specify gender, participant group and number: eg, M_PGY1_12 is a male, postgraduate year 1 , participant number 12). We also indicate when the excerpt comes from an audio diary entry. The transcripts have the following notations: ((double brackets)) indicates extra linguistic information; [square brackets] indicates additional clarification; ellipsis ... indicates missing words; 'italicised words in single quotations' indicate direct reported talk or thought and bolded words demonstrate narrators' emphasis.

\section{Theme 1: explicit conceptualisations of preparedness for practice}

Some participants across all stakeholder groups struggled to conceptualise 'preparedness for practice', as evidenced by their faltering talk (excerpt 1 , box 1 ). When they did begin to define the term, however, the majority focused on how preparedness meant passing exams in order to become a doctor, whereas a minority (from the CE, DPL and POL groups) made a distinction between passing exams and actually being prepared to work as a new graduate doctor. Participants from all stakeholder
Box 1 Explicit definitions of 'preparedness for practice'

Excerpt 1: "((Laughs)) [4s pause] I suppose it's really how we felt prepared for what we were going to face as we started work from medical school, and whether we felt like the training was adequate for what we were going to be doing..." (M_PGY1_19)

Excerpt 2: "it's a composite isn't it? It means they have the knowledge and the skills, they have the ability to organise themselves, and they have the communication emotional component... It's the whole package" (M_CE_55)

Excerpt 3: "... when they graduate on their first day of the ward... they have the skills and ability to undertake those activities of a foundation doctor... part of that I think would also involve recognising their own limitation "cause they're only out of university'" (M_HSP_07)

Excerpt 4: "it's a long term thing... it's preparation for a career in practice" (M_CE_31)

Excerpt 5: "not just for that first day, not just for that first month, not even just for that first year, but to give them a foundation where they feel competent and confident to practice in the longer term... issues such as patient safety... the moral dilemmas that they'll come across as time goes by and what to do when they fail" (M_CE_3)

Excerpt 6: "there is no way I think in any professional training that you can be fully prepared for the job you're going to do, because it's an academic training with some practical input..." (F_PPR_44)

Excerpt 6: "that's complicated... it's both the ability to complete the job required, but also to be able to do it without causing mental problems... I think a lot of people are able to do the job satisfactory, but in a great deal of psychological distress... [it's] about... being in a state of resilience..." (M_CE_21)

groups highlighted that performing as a new graduate doctor included possessing the knowledge, skills and behaviours expected of them, and included knowing limitations, prioritisation, managing stress, engendering patient trust and generally being a safe doctor (excerpts 2 and 3, box 1). Temporal aspects of preparedness also featured heavily in participants' talk across stakeholder groups. While short-term preparedness focused on graduates being able to hit the ground running (excerpts 1 and 3, box 1), long-term preparedness involved readiness for a medical career, focusing on psychological and emotional aspects of preparedness (excerpts 4 and 5, box 1). Interestingly, some acknowledged that an undergraduate degree in medicine could not fully prepare new graduates for this long-term preparedness (excerpt 6, box 1). Finally, preparedness was about knowledge and skills and about dealing with psychological distress and possessing good physical health and mental resilience (excerpt 6 , box 1 ).

\section{Theme 2: newly graduating doctors' preparedness across the GMC's outcomes for graduates}

This theme considers participants' narratives as a response to the broad question "how prepared are you (do you think medical graduates are) for practice?" We present our analysis according to the specific outcomes as set out in the GMC's outcomes for graduates. ${ }^{31}$ The subthemes that follow therefore include: doctor as scholar and scientist; doctor as practitioner and doctor as professional. It 
Box 2 Narrative excerpts for preparedness for scholar and scientist outcomes

Excerpt 1: "I understood the physiology of what was happening... I was able to grasp that she was not responding to the treatment, and even why... I did not feel comfortable having this patient under my care at night with just two doctors in the hospital... with no ICU [intensive care unit] available and no lab on site" (M_PGY1_01: audio diary)

Excerpt 2: "I mean I knew a lot about diabetes, but when I'm there on the ward and someone comes to me and talks about setting up a sliding scale because someone's levels are too high, I found I knew a lot about the receptors and all these sort of like lofty things about how they work... I didn't know well enough, properly, how to put in place the treatment for it..." (M_PGY1_19)

Excerpt 3: "in terms of dealing with actual things that came across, I'd say the theory was there, like hypoglycaemia, I could tell you exactly what to do and when to do it, and then when someone had hypoglycaemia I say where the kit is and I had never actually used the kit before, so I had this weird tube... I had an insulin syringe, I was just like 'what to do with this?' ... it was like this much between my theoretical knowledge and how to do it" (M_PGY1_25: audio diary)

Excerpt 4: "... there were some sort of glaring, glaringly weird things said which, you know, l'm thinking 'I didn't get an 0-level in biology and I know... that's [liver] not there' so perhaps they weren't that far ((laughter)) into the training" (F_PPR_38)

Excerpt 5: "it's very complex... you can't expect these very junior doctors to have all these insights... these days a lot of medical problems are not about taking a tablet to lower your blood pressure... it is about lifestyle... they've always been focused to rule out medical conditions that they have not focused on... what causes the pain... that is often the psycho-social and social environment" (F_CE_18)

is important to understand that we did not specifically ask about these outcomes due to our open and narrative approach to questioning. Furthermore, rather than neatly falling into single specific outcomes identified in the document, participants' narrated events were rich with detail, frequently cutting across more than one outcome domain. As such, many narratives were coded to multiple subthemes, with some demonstrating preparedness for one outcome and unpreparedness for another.

\section{Doctor as scholar and scientist}

This subtheme considers aspects such as medical graduates' abilities to apply biological, psychological and sociological principles and knowledge to practice and considers population health, healthcare improvement and research. Interestingly, very few participant groups contributed narratives to this subtheme. Most of the data came from PGY1s directly and focused on issues of biomedical scientific principles, with little data relating to psychological or sociological principles. There was a complete absence of narratives relating to population health, healthcare improvement or indeed research.

The vast majority of trainees' narratives related to situations where they felt prepared in terms of their biomedical scientific knowledge. Although some trainees narrated situations where they were able to translate this knowledge to the presenting patient, this preparedness was sometimes undermined by a lack of ward staff or clinical support (excerpt 1, box 2). Others admitted struggling to translate their knowledge into clinical practice (excerpts 2 and 3, box 2). Furthermore, PPRs commented on PGY1s' lack of biomedical knowledge or lack of ability to translate knowledge into practice (excerpt 4, box 2). In terms of psychosocial aspects, some clinical educators and PPRs felt that a holistic understanding of patient care was lacking in PGY1s' care (excerpt 5, box 2).

\section{Doctor as practitioner}

This subtheme considers various aspects of medical graduates' preparedness such as their abilities to: conduct patient consultations; diagnose and manage conditions; communicate effectively; prescribe; perform practical procedures and use information effectively in the workplace. The outcomes associated with 'doctor as practitioner' were most prevalent across all participant group narratives.

\section{Preparedness for patient consultations}

Patient consultations include history taking, full physical examinations and assessing patients' decision-making capacities. In terms of history taking, both PGY1s and others narrated how PGY1s seemed prepared to take patient histories (excerpt 1, box 3). However, PGY1s stated that they often felt underprepared for the high volume of patient consultations and anything unexpected or unusual regarding those consultations (excerpt 1, box 3). Other stakeholders commented that PGY1s had not yet understood their role in healthcare processes, lacking situational awareness (excerpt 2, box 3). Furthermore, when PGY1s transitioned into new wards they often encountered problems in terms of history taking for that particular specialty (excerpts 1 and 3, box 3). With respect to full physical examinations, PGY1s narrated their preparedness for conducting examinations (excerpt 1, box 3) and presenting their examination (and history) findings to their senior colleagues. Although different participant groups talked about PGY1s' preparedness for understanding how to assess patient decision-making capacity, many participants commented that they found such assessments challenging in practice (excerpt 4, box 3). However, from the perspective of patients, one PPR participant reported that his experience with 'very, very junior doctors' was positive, but added the caveat that these junior doctors had the benefit of having ' a lot of time to do it', suggesting that they were probably undergraduate medical students learning without the pressures of work (excerpt 5, box 3).

\section{Preparedness for diagnosing and managing conditions}

The majority of narratives coded to this theme came from PGY1s, who recounted both preparedness and unpreparedness for practice narratives in roughly equal measure. Multiple participant groups (including PGY1s, PGY2s, CEs and POLs) felt that PGY1 doctors were mostly prepared to diagnose and plan treatments when 
Box 3 Narrative excerpts for preparedness for practitioner outcomes

\section{Patient consultation}

Excerpt 1: "I was working today in pre-assessment clinic where we have to clerk patients that are for theatre... as medical student a lot of our time is spent clerking and examining patients so in that respect I felt um prepared for the situation... questions to ask and in what order... but... we didn't get taught in medical school how to clerk for a... pre-op assessment clinic... you're assessing someone's anaesthetic risk as well as... the risk from the surgery... it's quite a big responsibility" (F_PGY1_27: audio diary)

Excerpt 2: "they haven't got a clue what they're up to... they might be able to take the history... but... they don't seem to understand why... l'd use the term again, situational awareness... so you know classically in anaesthetics and theatres we talk about the situational awareness and that's about the environment that you're working in, the risks that are occurring, but it's having that wider view of the world..." (M_POL_32)

Excerpt 3: "sort of feeling a bit rusty in terms of obstetric history... it's difficult when you go into specialties from a previous rotation, because I was on medicine, you have your set of questions that you ask... and I suppose when I first took a history off... a[n] obstetric patient it was sort of remembering which subheading you need to put where and what you had to ask in obstetric history" (M_PGY1_30)

Excerpt 4: "they know the theory behind it all but I think they can do with a little bit of education or support from seniors... to fully understand what the connotations of going through the mental capacity act and stuff like that, they know all that, but I don't think they get a lot of training how they should apply it and what it does mean to the patient" (M_CE_28)

Excerpt 5: "yes they were very, very junior doctors who came and took histories from me and they did it very, very well... they had a lot of time to do it mind you" (M_PPR_25)

\section{Diagnosing and managing clinical conditions}

Excerpt 6: "During my first set of nights in surgery a nurse approached me to tell me that a patient had had an episode of coffee ground vomiting [usually the result of bleeding into the stomach]... I was recalling what I had seen before and working through the patient's symptoms and needs and dealing with them accordingly. I think I was able to do so because this patient was stable and I had time to think and act" (F_PGY1_05)

Excerpt 7: "but I think just the experience was pretty horrendous and something that I... wasn't prepared for sort of emotionally... the resuscitation was unsuccessful ..., and the child passed away... it's different whenever you practice on... the mannequins in the resus training, and even doing CPR, which l've done numerous times now, on elderly patients... you kind of get a bit cold to it, but certainly I wasn't prepared for... emotional trauma of taking part in a paediatric cardiac arrest" (M_PGY1_08: audio diary)

Excerpt 8: ". . the worse thing is when a patient comes in who is sick, they [PGY1s] just clerk, they ask them the questions, they write down the answers, they examine them, they write down examination findings, they do the usual bloods and they put them in a bed, and then twelve hours later or twenty-four hours later somebody more experienced will see them and think 'oh my god, what the hell's been happening here? This patient is desperately ill, we've missed an opportunity here'..." (M_CE_21)

Excerpt 9: "... actually there's no point in me speaking to the trainees, I need to go to the registrar because I need a discussion about the management and I don't think that l'll get that from the [PGY1]... if you go to a newly qualified [trainee] and say these two medicines aren't prescribed they may well write them up, which is really what you don't want" (F_HPE_28)

Excerpt 10: “... got someone who's still reduced level of consciousness... likely hit her head, so... I was halfway through talking to this lady, maybe ten minutes in, I could hear my consultant outside of the curtain... [he] sticks his head around the curtain and sort of gives me a bit of a look and beckons me out to come and talk to him... I felt the tone of the consultant's conversation was... sort of looking to leave this lady for a bit, give her some pain relief... so that's was what I did for the next ten minutes [l]... I think even with that experience... you can still do very different things, you can be very conservative and order a lot of tests and make sure you very much cover your back, equally you don't do that all the time because... you don't want to be over-testing people and also spending more money than we necessarily have" (M_PGY1_02: audio diary)

\section{Communicating effectively}

Excerpt 11: "my registrar basically said 'go and speak to the family'... I was like 'okay', so I explained what had happened to their dad... and... they just start firing these questions at you and you're kind of sitting there going 'uhmm, uhmm, I don't know... but I can find out for you'... and that was quite an uncomfortable moment because... it makes you feel quite incompetent... when it comes to a real situation at 2.00 am in the morning with someone's father, and someone's husband, and they're asking all these questions, there's two or three people crying next to you, the last thing you... can really remember is your fifth year lecture on stroke thrombolysis... it was quite intense" (M_PGY1_35: audio diary)

Excerpt 12: "I've never thought that we're all equal... so the people who are successful with patients at risk, or more demanding patients, I think with some extent that's a special kind of person... although it's possible to train individual doctors to become more understanding, unless they've really got it within them, I think er they're only going to go so far down that road of having a full understanding full of empathy, full willingness to spend time... I put that down not to their training, not to their age, not to the experience, but to themselves, the people... and some doctors will fit that bill... but not all..." (M_PPR_21)

Excerpt 13: "essentially it was a corridor conversation that happened between one of my senior nurses... with this trainee in the corridor... there was a challenge about the care that she'd [trainee] given to a patient and also there was like a prescribing issue as well... the poor doctor... was getting hammered verbally by the nurse in the corridor... it was basically like machine gunning the poor girl verbally in a corridor... the girl [trainee] did walk off the ward straight away crushed... we were trying to get her on bleeps later on [but] couldn't get her..." (F_HCP_24)

\section{Prescribing drugs safely, effectively and economically}

Excerpt 14: "there was a patient admitted with urosepsis (severe urinary tract infection) who was commenced on a regime of antibiotics, one of the antibiotics was then stopped which was called vancomycin where you have to load it on several levels, it was stopped abruptly, then 2 days later it was picked up on and I got asked to restart it. This is very new territory for me and l've never been told how to restart something like this before..." (F_PGY1_02: audio diary)

Excerpt 15: “... even things like IV morphine, like the nurses they won't do it, they expect you to just prescribe morphine and give an IV 'cause this person's in pain and they need it... and that is... quite worrisome... the one time I did that, it was it was for a guy who had some sort of blood cancer... 
Box 3 Continued

ended up having to phone up palliative care in one of the hospices 'cause... it was at night and I was really worrying about it but he was like rolling around in pain... I still went up the ladder 'cause I just wasn't... one hundred per cent sure about giving IV morphine at that point... so that was a bit scary" (F_PGY1_13)

Excerpt 16: "with the prescribing... they [PGY1s] will ask you a question... and you might tell them and they might just write it down without, let's say, engaging with you and sort of discussing the issues around it, and whether it's appropriate for that patient... so they know who's best to ask for help and realising that they do need to ask for help... sometimes they... see it as black and white... one dose being the only dose, whereas in reality they need to take a clinical judgement... so at first I would quite happily say 'oh well, it's this' and then realise that they were just writing down what I'd told them without any thought ((laughs))..." (F_HCP_82)

\section{Carrying out practical procedures safely and effectively}

Excerpt 17: "On a late shift in the Care of the Elderly building I was asked to take a blood sample for a group and cross match from an older gentleman who was anaemic... I went up to see the patient who needed to be transfused... I... obtained informed consent, checked the patient's details carefully and managed to insert the venflon and take the group and cross match blood sample together... The following day... I followed up on the gentleman in question. He had been stable overnight and was receiving his transfusion. I felt satisfied that I facilitated this patient's transfusion in a manner that had minimised risk and maximised benefit". (F_PGY1_06: audio diary)

Excerpt 18: "A time that I felt unprepared was when I was called to see an elderly female on the urology ward. She had been in for several weeks and when I was called to see her she was vomiting bile... I decided... to start her on IV fluids, make her a nil by mouth and request an abdominal X-ray. I wasn't quite sure what I was dealing with... once I [had] seen the abdominal X-ray which showed dilated loops of small bowel, I then sought some senior help... I said to her [senior house officer] what my management had been and how I was thinking of putting an NG tube down she agreed with me... I asked one of the senior nurses on the ward to assist me, and hence I put down my first NG tube.... I felt quite unprepared at doing it... I managed to successfully introduce the NG tube. It was quite a daunting experience... during the ward round in the afternoon... the urology registrar... commended the management that I had done". (F_PGY1_03: audio diary)

\section{Using information effectively in the clinical environment}

Excerpt 19: "[we are] often the... first doctor to see a patient when they come into hospital, l've realised since l've done the job, how important that first clerking is, so for example, documenting what's bought the patient into hospital... the other day when I was seeing a patient, um had written half of their clerking... a couple of pages of writing... and got called away to do something else briefly, l'd referred my patient to medicine and I came back and the patient had been transferred already to medical ward a lot sooner than I thought, and I actually hadn't finished writing for the patient... I remember being really, really stressed out about this... I felt really terrible that this patient had gone with only half a clerking, so I had to scoot after them to the medical ward and finish writing, because I thought this would reflect really badly on me... I think that little outcome made me realise how important our documentation is... and this sort of accountability and traceability is a really important part of being a good first year doctor..." (M_PGY1_08: audio diary)

cases were relatively straightforward (excerpt 6 , box 3 ). However, PGY1s narrated feeling less well prepared for the diagnosis and management of acutely unwell patients, particularly in emergency situations when they struggled to find information, manage uncertainty and emotions and prioritise (excerpt 7, box 3). While some trainees narrated feeling better prepared for making diagnoses than patient management, others such as senior doctors flagged cases of PGY1 doctors missing diagnoses and contributing to serious patient safety issues (excerpt 8 , box 3). Furthermore, PPRs expressed concern that PGY1s preferred simple diagnoses, being reluctant to consider greater complexity or to support patients when asking for a second opinion.

Some PGY1s indicated that decisions were not purely their own responsibility but were that of the wider interprofessional team. Here, PGY1s narrated dilemmas around when they should escalate decisions with others. While PGY1s' narratives reported them being proactive in terms of diagnosis and management, HCP participants often indicated that PGY1s were merely reporting diagnosis and management in patients' notes rather than proactively acting on their investigation findings. Furthermore, some HCPs talked about how they went over PGY1s' heads to discuss things directly with their superiors as they believed the PGY1s would just follow orders rather than engage in serious discussion about patient treatments (excerpt 9, box 3). Interestingly, both employers and clinical educators expressed their concern about PGY1s' abilities to glean sufficient contextual information about patients in order to consider diagnoses and management holistically. Indeed, PGY1s' narratives tended to focus on the clinical aspects of diagnosis and management rather than broader psychosocial or cultural aspects and their narratives rarely included them involving patients, families or carers when making diagnoses or developing management plans.

PGY1s were felt to request too many expensive patient investigations, with trainees reporting overordering investigations for fear of missing something (excerpt 10, box 3). Interestingly, trainees talked about witnessingor deferring to-their seniors' investigation patterns, which gave them the necessary role modelling and reflective experience from which to consider their own place in financial aspects of care (excerpt 10, box 3 ).

In terms of factors that contributed towards PGY1s' preparedness, some trainees cited their confidence in themselves, positive relationships with their supervisors and/or wider team, and prior rote learning of fire drills (eg, the ABCDE approach) and simulation learning as being facilitative (especially the learning of fire drills for emergency situations). Contrary to this, other PGY2s and some PGYls felt that simulation learning comprised insufficient preparation for real-world scenarios where 
managing sick or dying patients, sometimes without support, was commonplace (excerpt 7, box 3).

Finally, despite the quantity of data in our study that mapped onto this subheading of diagnosis and management, we found little evidence for some factors specified in the GMC's outcomes for graduates, including trainees supporting patients' self-care, and identifying features of abuse in patients.

\section{Preparedness for communicating effectively with patients and colleagues}

While there was evidence in some participants' narratives that trainees could communicate effectively and sensitively with patients and families, several areas of underpreparedness were commonly narrated by PGY1 and PGY2 doctors in terms of patient-orientated communication, including: communicating with particular 'types' of patients (eg, patients with mental health conditions, patients who are emotional, patients with English as an additional language and/or highly informed patients); managing complaints and breaking bad news (excerpt 11, box 3). Once again, the issue of learning via simulation was deemed inadequate for communication preparedness (by PGY1, PGY2, DTPL and HCP groups), due to the unpredictable nature and complexity and of real-life interactions. Indeed, trainees commonly narrated communication challenges with patients that were emotionally problematic for them, with trainees sometimes narrating fears for their physical safety. Finally, patients variously narrated events concerning junior doctors' preparedness for communication. The general consensus was that communication skills were lacking in junior doctors, but that these skills were also lacking in their seniors too. Thus, we had multiple narratives from patient groups in which they focused on more senior consultants and the issue of abruptly breaking bad news, leading to patient distress. Some participants felt that such role models had a significant influence on the development of junior doctors' communication skills, especially those early on in their careers. Others discussed the issue of individual differences in people, rather than this being a training issue (excerpt 12, box 3). However, it was noted that the patient group, more than other stakeholder groups, tended to refer to a range of sources (eg, their friends, family and media) when presenting their opinions, rather than just first-hand experiences..$^{28}$ Furthermore, patient participants' first-hand experiences were generally more positive than when they discussed these secondhand stories.

While various participant groups indicated that PGY1s were prepared for communicating with colleagues, participants also narrated communication challenges with respect to multiprofessional working such as clinical disputes with senior medical or nursing staff, difficulties in gaining support from senior medical staff or HCPs and handovers with insufficient information received. Occasionally, serious communication breakdowns between nurses and PGY1 doctors were narrated, including confrontation, emotional distress and ongoing teamwork problems (excerpt 13, box 3). Interestingly, junior doctors narrated the importance of learning on the job, suggesting that everyday experiences of interacting with different healthcare professionals enabled them to develop the skills they needed over time (see 'preparedness for learning and working effectively in multiprofessional teams' section below).

\section{Preparedness for prescribing drugs safely, effectively and economically}

Generally, our data suggest that medical graduates were less prepared for prescribing. Interestingly, it was the HCP group who provided the strongest evidence around graduates' unpreparedness, with the PGY1s narrating roughly equal numbers of prepared/unprepared events. While some graduates narrated how practising prescribing skills during medical school and interprofessional team working afforded adequate learning opportunities, others narrated prescribing difficulties resulting from their limited workplace prescribing experiences, the complex (and sometimes urgent) nature of the prescribing event, alongside a lack of support on the wards (excerpts 14 and 15, box 3). They frequently narrated referring to the British National Formulary (BNF) during ward-based prescribing, especially for double-checking their drug selection and dose calculations. Interestingly, PGY2 doctors discussed their own unpreparedness for prescribing on graduation and new PGY1s' unpreparedness, sometimes talking about how they tried to educate PGY1s about prescribing because they understood their lack of prescribing practice. Other stakeholders (eg, DTPL, EMP groups) narrated that PGY1s lacked basic pharmacology understanding and were unable to grasp the concept of economic prescribing. Participants in the HCP group highlighted that although PGYls knew how to access prescribing support, they lacked prescribing knowledge and reasoning, were less prepared to write legally controlled drug prescriptions or undertake adequate drug histories (excerpt 16, box 3). A few prescribing errors were narrated and there was a view that PGYls were unaware of common error sources and safety checks.

\section{Preparedness for carrying out practical procedures safely and effectively}

PGY1s narrated numerous events in which they portrayed themselves as prepared for everyday practical procedures such as obtaining blood samples, inserting cannulas, inserting urinary catheters and carrying out ECGs (excerpt 17, box 3). While PGY1s explained that certain processes (eg, ABCDE) had been 'drilled into' them during their undergraduate education, they explained that their confidence in performing practical procedures had grown during PGY1 as they learnt on the job performing practical procedures repeatedly on real patients. PGY1s, however, narrated that routine procedures could be problematic at times, for example, when they experienced difficulty in accessing veins, resulting in 
concerns of unpreparedness. As with prescribing, when PGY1s felt less prepared, they reported how they sought out (and sometimes insisted on) support from seniors in order to maintain patient safety (excerpt 18 , box 3 ).

\section{Preparedness for using information effectively in the clinical environment}

Similar numbers of preparedness and unpreparedness narratives for using information effectively were elicited from our participants. While PGYls narrated being prepared for some aspects (eg, accessing hospital services via computers and using Apps for information), they seemed less prepared for others (eg, documenting procedures, documenting initial clerking and accessing patient notes: excerpt 19, box 3). Many PGY1s narrated incidents of incomplete patient notes and/or illegible handwriting. Problems using information effectively in teams and having insufficient information when requesting the assistance of other healthcare professionals were also included in PGY1 doctors' narratives. The POL and EMP groups highlighted the importance for PGY1s to keep clear patient records and suggested that this was an area in need of further training.

\section{Doctor as professional}

In this section, we consider participants' narratives about PGY1s' preparedness for professional aspects of work, including ethical and legal aspects, reflection, learning and teaching and multiprofessional team-working.

\section{Preparedness for ethical and legal aspects}

While approximately half of the narratives classified to this theme indicated neither preparedness nor unpreparedness, the remaining narratives suggested that new graduates were relatively unprepared for ethical and legal aspects. Notably, most of these came from graduates. While they narrated preparedness for activities such as obtaining valid patient consent and completing death certification, they also narrated their unpreparedness for more complex situations like domestic violence cases, confidentiality issues around patients brought into the hospital by police, patients wishing to self-discharge from hospitals and completing 'Do Not Attempt Resuscitation' (DNAR) forms (excerpt 1, box 4). Although they sometimes narrated their knowledge of ethical principles and occasionally provided examples of situations in which they challenged seniors about their professional behaviours, they also revealed some uncertainty about how to act appropriately at times (excerpt 2, box 4), sometimes seeking advice from their seniors (excerpt 3 , box 4). Interestingly, they often narrated feeling unprepared for their own emotional reactions during such complex events. Other stakeholders (PGY2, DTPL, GOV and EMP) discussed medical graduates' overall preparedness around patient-centred care and ethical reasoning, although sometimes situations suggested that new medical graduates were less attentive to their professional self-care and self-presentation (excerpt 4, box 4).
Preparedness for reflecting, learning and teaching others

There was a paucity of data on reflecting, learning and teaching others, although medical graduates often touched on these issues, sometimes summarising a take away message for future learning based on the events narrated. Effective time-management and the maintenance of work-life balance were narrated as challenging. Participants in several groups (eg, PGY1/2s, CEs and DTPLs) narrated events in which new medical graduates failed to work efficiently, such as taking too long to clerk patients, asking irrelevant questions, requesting unneeded tests and prioritisation skills (excerpt 5 , box 4). Medical graduates' accounts were linked to fatigue-the less sleep, the worse their time management was-and their general lack of experience in what comprised an essential task. The PPR group empathised with the difficulties that new graduates faced in terms of juggling many different demands and linked this with junior doctors developing mechanisms to block out patients' demands (excerpt 6 , box 4). Some medical graduates narrated receiving excellent teaching and feedback (excerpt 7 , box 4 ), and often discussed how they were trying to address their shortcomings. Graduates also narrated events where they felt well prepared to teach undergraduate medical students on placements, often citing their own inadequacies and a desire to address this in the next cohort of graduates (excerpt 8, box 4).

\section{Preparedness for learning and working effectively in multiprofessional teams}

Despite having some communication problems (as discussed above), medical graduates commonly narrated positive experiences of working as part of a multiprofessional team, frequently citing nurses as making a positive contribution. Other stakeholders also narrated events in which today's medical graduates were contrasted favourably with previous generations of PGY1s. While medical graduates constructed themselves as being relative newcomers to the team, they explained being prepared to learn from others (excerpt 9, box 4). They reported how working with other healthcare professionals, such as social workers, provided them with different ways of thinking and working. They also narrated their attempts of building positive working relationships with other healthcare professionals, for example, through introducing themselves, taking time to get to know others, building trust and resolving conflict. Both newly graduated doctors and HCP participants most often cited nurses as key players. While nurses could be a source of conflict for PGY1 doctors, as illustrated above (excerpt 12, box 3), they were also described as looking out for graduates due to their novice status. Indeed, newly graduated doctors' narratives frequently focused on them consulting nurses on ward practices, in preference to their senior medical clinicians, and for assistance when undertaking unfamiliar practical procedures (excerpt 10, box 4). Some graduates talked about feeling pressurised when other healthcare professionals wanted them to make decisions 
Box 4 Narratives excerpts for preparedness for professional outcomes

\section{Behaving according to ethical and legal principles}

Excerpt 1: "... all the seniors are then scrubbed in theatre leaving me as the most senior member on our team, which therefore meant it fell to me to actually do the 'do not resuscitate' form... and it's something that I didn't feel particularly confident with or happy doing" (M_PGY1_28: audio diary)

Excerpt 2: "She [the patient] had the diagnosis of [eating disorder diagnosis]... was admitted late at night and required an NG tube placement. This wasn't one of my patients, but I was allowed to observe the NG tube being placed... mainly because I haven't - I've never done one and I was actually told off about not knowing how to put one in... anyway, this patient didn't really want an NG tube... I was very torn ethically about this particular patient... It took three people to get the tube down which shouldn't really be the case...I was very uncomfortable with the fact that she was basically being force-fed" (F_PGY1_06: audio diary)

Excerpt 3: "I rang the ward and told them I'll be back in a minute to write up some fluids for a patient, and I got back and they'd already been given by one of the nursing staff... but they'd given something that is not prescribed, and you have to look at the scenario and think... 'should I raise this as an issue or should I not? and one of my registrars said that really if you go around trying to correct every bit of not-quite-right practice, you just give yourself a headache and create a lot of nightmares..." (M_PGY2_08)

Excerpt 4: "I have, on several occasions... [seen] trainees coming in inappropriately dressed... and I find it fairly intolerable... my male consultant colleagues find this a really difficult area because... if they tell females that they think that they're inappropriately dressed, they worry that the female will see this as bullying or harassment... I feel that it shows a little bit of a lack of understanding and respect for the patients to come on the ward inappropriately dressed" (F_GOV_28)

\section{Reflecting, learning and teaching others}

Excerpt 5: "time management... that's one of their [PGY1] major challenges, the prioritising and time management... you can just see when they first start, when their... bleep goes twice at once, you'll hear them... say to the nursing staff, 'which of these things should I do first? ..." (M_CE_16)

Excerpt 6: "I think that's true of junior doctors as well because the turnover on wards and everything... and the complexity of the conditions that are on wards these days, they're trying to learn how to deal with all that. . . and at the same time ((laughter)) regard this person as a human being that they're interacting with, it must be very, very difficult... I imagine as a junior doctor because you've got the pressure coming from the patient... but you've also got the expectations of your senior doctors, and you've got to get through this, and you've got to do the bloods, you gotta do that, you gotta do... you're torn between them and so gradually you develop mechanisms like you're on your computer to sort of block out the demands of the patient" (M_PPR_34)

Excerpt 7: "Yeah I've got one [clinical teacher] who, she was our registrar during my first job... she was particularly good because... she was very supportive and happy to help with anything... she would give you advice about who to speak to, ... and she would get me to talk through why I thought of each differential diagnosis and what I was going to do about it, and then gave me feedback and did assessments and things for me..." (F_PGY2_12)

Excerpt 8: "when you've got students with you... certainly getting them to do some of the things that I would have wanted to have done as a medical student to get experience was some of the things that l'm reflecting on now, like making decisions, so now l'm trying to get the students... to try and make those decisions with support while they're students as well..." (F_PGY2_8)

\section{Learning and working effectively in a multiprofessional team}

Excerpt 9: "taking care of the elderly, there's like multidisciplinary meetings every week... so you have the consultants there, you'll have the occupational therapists, the physiotherapists, the social workers, all like in the same room... the consultant will say how they're doing medically and then OT [occupational therapist] will say how they're getting on... they able to climb the front steps... you get a really good impression of the whole patient ... the physiotherapist will keep you right... particularly with mobilising them... so yeah l've found it really good working with them actually" (M_PGY1_14: audio diary)

Excerpt 10: "nursing staff, who are really helpful... especially in those emergency situations when you were waiting for someone more senior and they could be doing stuff for you while you were trying to work out what was going on... just telling you about how things worked on a ward... you'd often be asking 'so what would you normally be doing in this situation? they'd be like 'well this is what they done before' or you know 'this is what we normally give in this situation' and they were just a real fountain of knowledge" (F_PGY1_24)

\section{Protecting patients and improving care}

Excerpt 11:

"M_PPR_45: it seems to me... both nursing and medicine have retreated into themselves to a certain extent and they seem to be... the sort of management that is only concerned with money and ticking boxes... there is not this sense of 'we are the champions of the patient' and 'we care about the patient'... and 'we are going to fight for the patient'... probably happens in some places- but it doesn't seem to be a normal thing, and you see the way Trusts put gagging clauses into contracts... that's terrible... and yet it is often the junior doctor and the junior nurse that pick up the things that are going wrong... but where do you go? They're new aren't they, they're new

F_PPR_44: they're new and they identify more closely... you know for them, too, it's an alien environment

F_PPR_43: of course it is yeah...

M_PPR_45: I was talking about peer support, but yes, you still need the capacity to have a whistle-blower because... if it's your consultant... you want to complain about, then there are sensitivities...

F_PPR_44: you need to be able to talk to people

M_PPR_45: yeah

F_PPR_44: before you get to the whistle-blowing stage... you need to have a group of experienced people that you can talk over situations that you've been in to get them into perspective, and if necessary, to whistle-blow, but sometimes it's more simple than that

F_PPR_43: of course it is"

on clinical aspects that they were unsure about. Occasionally, graduates narrated witnessing team members' inappropriate behaviour, which caused dilemmas around how they should respond.
Protecting patients and improving care

Overall, participants' narratives suggest that graduates are less prepared in this area. PGY1 and PGY2 participants talked negatively in terms of coping with uncertainty 
and change: uncertainty about their diagnoses, when seniors changed their minds and ethical issues (excerpt 13, box 3). Their positive talk around uncertainty and change focused on how repeated exposure to similar events led them to cope better. Several PGY1s (and some DTPLs) narrated their understanding of healthcare improvement, describing their involvement in audits and projects. Participating in audits was thought to lead to PGY1s' broader understanding of the NHS. Healthcare improvements also work at a more interpersonal level. Consider the interaction between members of one of our patient groups (excerpt 11, box 4), in which they discuss the issue of junior doctors and nurses who witness poor patient care. Here, they highlight the issue that junior doctors are more closely aligned with patients' perspectives than their seniors, due to them also being in an 'alien environment', yet it is often their seniors who they witness breaching patients' safety or dignity. For junior doctors, this creates a dilemma around whistle-blowing (in the words of the PPR participant, although the GMC prefer the term 'raising concerns'). The conclusion that these patients come to is that, provided with the necessary support, junior doctors can make sense of what they see and subsequently make informed decisions around whether or not to whistle-blow. In addition to direct patient care, occasionally PGY1s mentioned self-care, understanding their need for appropriate levels of rest, nourishment and work-life balance. Interestingly, these aspects were only narrated in relation to the benefits they will have on patient care. Some of the PPR group participants also highlighted this issue, although their focus was more around how junior doctors were so overworked that they were not alert, which was deemed detrimental to patient care. As touched on earlier, PGYls and other stakeholders felt that they were generally unaware of (or unconcerned about) the financial consequences of their practice (excerpt 9, box 3), with PGY2s believing that cost efficiency was only appropriate further on in their careers.

\section{DISCUSSION}

This paper set out to address two research questions. In relation to the first question focusing on stakeholders' conceptualisations of preparedness for practice, participants sometimes struggled to articulate preparedness when specifically asked to define the concept. When they did, their understandings varied by the constituent aspects of preparedness (eg, knowledge, skills, behaviours and emotional aspects) and time (eg, short-term vs longterm). Furthermore, throughout the remainder of the interviews, participants' implicit conceptualisations of preparedness for practice also reflected these factors as they narrated their own experiences of observing and interacting with newly graduated doctors. Although previous research has explored preparedness in terms of clinical skills and procedures (eg, communication skills, examination skills and practical procedures), and other studies have considered issues around junior doctors' well-being, ${ }^{13} 32$ to our knowledge, our study is the first time that research focussing on the issue of whether graduates are prepared for practice has included behavioural and emotional aspects. Furthermore, since the primary focus of current research is around new graduates' shortterm preparedness (ie, preparedness for their role as PGY1 doctor) it appears that in general, researchers' understandings of this concept are more limited than those of our participants. ${ }^{16-20}$ This is also echoed in the GMC's outcomes for graduates document that focuses on knowledge, skills and behaviours, ${ }^{31}$ despite recognising the importance of resilience for doctors.

In relation to our second research question around various stakeholders' perspectives of recent medical graduates' preparedness, on the one hand, we found areas of consistency across stakeholder groups (eg, problems translating knowledge into practice), while on the other, we found contradictory findings, where graduates might perceive themselves as prepared but other stakeholders deemed them less prepared (eg, diagnosis and patient management). This pattern of consistency and inconsistency is echoed in previous quantitative research examining PGY1s' and their supervisors' opinions of PGY1s' preparedness for practice. ${ }^{33}$ What is different in our study, however, is the rich narratives based on real events experienced by different stakeholders. It is within these narratives that we can better understand the nuances of preparedness. For example, in terms of diagnosis and management, our data reveal that this difference in opinion lies in issues such as simple versus complex cases, perceptions around PGY1s' reliance on carrying out instructions (rather than engaging in discussions), and their sometimes powerful emotional reactions to difficult clinical situations. ${ }^{30}$ An understanding of these nuances enables a more sophisticated appreciation of the concept of preparedness, which recognises that preparedness is not binary, an aspect that was not specifically highlighted when participants were asked to define the concept. From here, educators are better able to develop educational and support systems appropriate to the specific mechanisms at play.

With respect to preparedness, if we are to make a list, our data suggest that medical graduates were mostly thought to be prepared for: history taking and physical examinations; diagnosis and management of simple cases; straightforward communication with patients and their families; straightforward communication with medical colleagues; openness for learning and working in multiprofessional teams; everyday practical procedures (eg, taking blood, inserting cannulas); some aspects of using information in the clinical environment (eg, accessing hospital services via computers) and straightforward ethical and legal aspects (eg, obtaining valid patient consent). These findings extend what we already know about UK junior doctors' preparedness for practice. ${ }^{10}$ For example, there has been a paucity of information on medical graduates' preparedness for multiprofessional team-working, 
although this limited and inconsistent evidence suggests that multiprofessional team-working is an area of relative unpreparedness. ${ }^{35}$ Furthermore, what our research adds to this literature is the multifaceted nature in which these 'preparedness' events occur alongside the deeper issue of what it means to be prepared: knowing how versus knowing why, knowing what it means and knowing what next. Indeed, our work calls into question the very notion of check-box approaches to preparedness for practice. ${ }^{18}{ }^{37-39}$ For example, our research confirms what we already know-that medical graduates can clerk patients: take their history and perform physical examinations. ${ }^{10}$ But our research sheds light onto their situational awareness, knowing the purpose of these activities (eg, preoperation assessment vs management of illness) or the ramifications (eg, what it means for the patient), which is often lacking. As such, our research unpacks what it actually means to know something and the limited utility of 'check-box' questionnaire research approaches. ${ }^{1417193840}$ Additionally, the issue of situational awareness further expands on our conceptualisation of preparedness for practice, pointing to the necessity for this to be facilitated during students' undergraduate years. However, it is worth noting that while medical students mature as they go through their undergraduate medical education, their development is not constrained to this environment, but necessarily interacts with their personal world outwith their studies. And it is within and between these two worlds that the emotional and psychological aspects of themselves develop. Thus, merely adding 'situational awareness' to the check-box is not the answer.

Regarding unpreparedness, in summary, medical graduates are mostly thought to be less well prepared for: applying biomedical scientific knowledge to clinical practice; psychosocial aspects of patient care; the high volume of patients requiring history taking and physical examinations; diagnosis and management of complex cases and acutely unwell patients; challenging communication with patients and their families (eg, breaking bad news); communication in multiprofessional teams; prescribing; some aspects of information management (eg, documentation); complex ethical and legal aspects (eg, DNAR forms) and effective time management and maintenance of work-life balance. Although some of these aspects have been found in previous studies exploring UK junior doctors' preparedness for practice, ${ }^{10}$ again, our study reveals further nuances around the issue of unpreparedness. For example, previous research suggests that graduates are prepared in terms of their knowledge of behavioural and social sciences for medical care and their recognition of the social and emotional factors in illness and treatment. ${ }^{17394142}$ However, there was a perception in our study, by both clinical educators and patients, that graduates failed to consider the psychosocial aspects of patient care and even developed mechanisms through which they could avoid patients' demands. Furthermore, medical graduates failed to mention these aspects in their audio diaries when describing their clinical reasoning and patient encounters. Thus, it seems that this might be an area in which medical graduates are, indeed, knowledgeable, but one in which they fail to translate their knowledge into everyday practice (as such, there is a distinction between 'knowing what' and 'knowing how'). Many PGY1s' narratives in our study are replete with accounts of complex and uncomfortable situations, which comprise 'new territory' for them. They sometimes explicitly report struggling to remember their classroom learning in the face of multiple interactional and contextual demands (eg, middle of the night, distressed patients, competing requests, etc). It is hardly surprising therefore that the cognitive capacity of these newly qualified doctors is challenged as they encounter high-stress situations alongside expected responsibilities, leading them to momentarily 'forget' learning that they may not have previously used in practice.

Relatedly, PGY1 participants in our study talked about the importance of learning on the job in terms of developing their preparedness for practice, particularly in relation to practical procedures and communicating with multiprofessional teams, as has been suggested previously by other researchers. ${ }^{20}$ While previous authors have discussed the importance of experiential and sociocultural learning theories in terms of preparedness for practice, ${ }^{1720}$ we instead draw here on Eraut's thinking about informal learning in the workplace. ${ }^{43}$ Indeed, informal learning includes: 'implicit, unintended, opportunistic and unstructured learning, ${ }^{43}$ and can be of three types varying by level of learning intention: implicit (unconscious); reactive (near-spontaneous) and deliberative (considered) learning. ${ }^{43}$ Eraut $^{43}$ highlighted various informal learning outcomes in the workplace including task performance (eg, communication with diverse people); role performance (eg, handling ethical issues); awareness and understanding (eg, understanding one's own organisation); academic knowledge and skills (eg, applying theory to practice); personal development (eg, ability to learn from experience); decision-making and problem-solving (eg, generating and evaluating options); teamwork (eg, collaborative work) and judgement (eg, prioritisation). Such informal learning outcomes, similar to those aspects of unpreparedness identified above, are thought to come about through participation in group tasks, working alongside others, undertaking challenging activities, and working with clients. ${ }^{43}$ Therefore, much of the unpreparedness we report might only be developed through informal workplace learning during the first two postgraduate years, unless significant change happens within undergraduate medical education to allow for final year medical students' meaningful participation in workplace activities such as prescribing. ${ }^{44}$

\section{Methodological limitations and strengths of the study}

Our study is not without its challenges, however, and these must be taken into consideration when interpreting our results. Given the participant-led nature of our narrative interviews and longitudinal audio diaries, 
participants volunteered their experiences of graduates' preparedness/unpreparedness without prompting for specific GMC graduate outcomes. Therefore, we collected sparse data (eg, on preparedness for reflecting, learning and teaching others) or no data (eg, on preparedness for population health, healthcare improvement and research) for some GMC graduate outcomes. We cannot be sure why these were not mentioned but we suspect that they did not readily come to the minds of stakeholders, which is an important finding in itself. Therefore, our findings present only a partial picture of UK graduates' preparedness against all GMC graduate outcomes. ${ }^{31}$ Finally, given the voluminous data collected (ie, 2186 narratives from 185 participants across 111 interviews), we found it impossible to present all seven identified themes in sufficient depth in this one paper. We were also unable to present longitudinal results here, in addition to the cross-sectional findings. Therefore, in this paper we report on two of our themes; the remaining themes and analyses are presented elsewhere. ${ }^{927-30}$

Despite these challenges, our study has strengths. It is one of few to explore multiple stakeholders' perceptions beyond graduates and their supervisors ${ }^{10}$ including previously under-represented groups such as PPRs and policy and government officials. Furthermore, previous studies have explored PGY1s' preparedness for practice employing qualitative data collected at a single timepoint, ${ }^{45-47}$ or fixed time-points longitudinally, ${ }^{20}$ or via quantitative retrospective surveys of graduates (and occasionally their supervisors). $.^{17} 33 \quad 4148-53$ Our study employs both narrative interviewing and longitudinal audio diaries, thereby enabling us to capture narratives of events close to their time of occurrence, increasing the details of those events within our data. As such, we address the acontextual nature of event reporting, plus recall challenges, found in previous literature. ${ }^{21}$ We have collected a large amount of qualitative data (nearly 100 hours) from stakeholders across four UK sites (England, Northern Ireland, Scotland and Wales). This, coupled with the similarities between our findings and other recent UK-based preparedness for practice studies, and alongside the advances we have made in terms of the complexities and nuances of the data, means that our findings are likely to be transferable across the UK. Furthermore, we employed a team-based approach to our qualitative data analysis, enhancing both our study rigour and reflexivity. Our large research team came from diverse disciplinary backgrounds (medicine, social sciences, biomedical sciences, healthcare education and education), bringing different expertise, expectations and understandings to our interpretations, leading to a more thorough analysis of our data. ${ }^{54}$ Finally, we classified participants' narratives in terms of relative preparedness according to how they constructed the events. Thus, what we present here is an accurate picture of stakeholders' perceptions of newly graduated doctors' preparedness rather than objective assessments or our classifications. Indeed, there might be instances where a situation was narrated as one of unpreparedness but that when seen through the eyes of another, reveals a level of preparedness. For example, that newly graduated doctors narrated referring to the BNF during their ward-based prescribing as them feeling unprepared for prescribing-double-checking their drug selection and dose calculations-could be constructed by others as evidence of preparedness in terms of awareness and professionalism. This disparity of interpretation is worth noting in order to evaluate the utility of our results.

\section{Implications for educational practice and further research}

Despite these methodological challenges, there are numerous implications for educational practice and further research. In terms of educational practice, we think that a lack of shared understanding of what preparedness for practice actually is, could lead to misunderstandings and misplaced expectations about graduates' workplace performance. Furthermore, across a range of factors reported in our results-including communication in the workplace, prescribing, learning and working effectively in multiprofessional teams-our participants narrated a range of problematic situations leading to feelings of unpreparedness. Therefore, we think that the development of shared understanding (and thus expectations) of preparedness for practice between graduates and other stakeholders as part of graduates' transition interventions is key. Our findings also suggest that such transition interventions should look beyond short-term preparedness for the PGY1 role, and also consider long-term preparedness for aspects such as medical careers, and psychological and emotional aspects of preparedness. ${ }^{1355}$ Second, as trainees, junior doctors are supervised. With this understanding of preparedness as an ongoing process, our study holds implications for supervisors as guardians of patient safety. Junior doctors require the right balance of supervision (to safeguard patient safety) and autonomy (to facilitate their development). This balance develops with supervisory experience and can benefit from appropriate training. ${ }^{56}$ Additionally, our findings suggest numerous GMC outcomes for which medical graduates are thought to be less well prepared, largely because, we would argue, they lack sufficient informal workplace learning opportunities during their undergraduate education to develop these capabilities. ${ }^{44}$ Indeed, we believe that PGY1s' ability to manage complex and challenging situations will only develop through increased informal workplace learning opportunities. We therefore recommend that medical educators re-consider their final year medicine curriculum and increase the proportion of time that medical students spend participating meaningfully in multiprofessional teams as part of informal workplace learning: indeed, this is already beginning in terms of an extension to current assistantship periods. ${ }^{13} 57$ Alternatively, we need to recalibrate our expectations of what PGY1 doctors should be able to do on graduation based on our appreciation that they will only become fully prepared for certain aspects once they are in post. For this latter approach, a greater focus on the formal and informal 
clinical supervision of PGY1 doctors is key; supervision that emphasises the formative (educational) aspects of supervision and privileges the restorative (supportive) aspects of supervision. ${ }^{58}$

In terms of research, we know from this and other studies ${ }^{10}$ what UK graduates are typically thought to be less well prepared for, based on quantitative surveys and qualitative interviews. Further research is now needed employing observational methods to explore further those aspects of unpreparedness. For example, innovative methods such as video-reflexive ethnography (VRE) could be used to explore the complexities of PGY1s' everyday experiences. As an educational intervention in itself, VRE has been used to stimulate discussion of PGY1s' prescribing among the multiprofessional team in order to further develop junior doctor prescribing. Such methodologies will allow us to unpack the complexities of informal workplace learning more fully.

\section{Author affiliations}

${ }^{1}$ Chang Gung Medical Education Research Centre (CG-MERC), Chang Gung

Memorial Hospital, Gueishan, Taiwan

${ }^{2}$ Cardiff University, Cardiff Unit for Research and Evaluation in Medical and Dental Education (CUREMeDE), Cardiff, UK

${ }^{3}$ Centre for Medical Education, Queen's University Belfast, Belfast, UK

${ }^{4}$ English Department, Stockholm University, Stockholm, UK

${ }^{5}$ Exeter Medical School, University of Exeter, Exeter, Devon, UK

${ }^{6}$ Salisbury District Hospital, Salisbury, UK

${ }^{7}$ Centre for Research in Professional Learning, University of Exeter, Exeter, UK ${ }^{8}$ Monash University, Monash Centre for Scholarship in Health Education (MCSHE), Faculty of Medicine, Nursing \& Health Sciences, Melbourne, Victoria, Australia

Acknowledgements The authors wish to thank the wider research team for their involvement in the study design, helping to secure funding, ethics approvals, analysis and data collection (Judith Cole, Grit Scheffler and Christopher Jefferies). The authors would like to thank Dr Philip Bell, the Patient and Public Representative (PPR) associated with the wider study for his assistance in developing the interview protocol for the PPR groups. The authors would like to thank all of the participants for taking part in this research and sharing their narratives, with special thanks to Dr Rosie Tope (PhD), one of the carers who participated in the study, who explicitly asked that her and her husband, Dr Roy Nolan, be acknowledged.

Contributors LVM, CER, KM, AB and GJG contributed to the conception of the study. LVM, CER, KM, AB and GJG designed the work. KK, NK and CEK contributed to the acquisition of the data. All authors contributed to the analysis and interpretation of data. LVM, KM and CER drafted the initial manuscript. All authors revised the manuscript critically for important intellectual content and gave their final approval of the version to be published. LVM is the guarantor, agrees to be accountable for all aspects of the manuscript, has access to the data, made the final decision to submit and will ensure that any questions relating to the accuracy or integrity of any part of the manuscript are appropriately investigated and resolved.

Funding The study was funded by the General Medical Council, who were kept informed of progress with the collection, analysis and interpretation of data, but the researchers remained independent from the funders. The GMC have given their approval for the publication of this paper.

Competing interests None declared.

Patient consent Not required.

Ethics approval Central University Research Ethics Committee (CUREC) Cardiff University; Joint Research Ethics Committee, School of Medicine, Dentistry and Biomedical Sciences, Queen's University Belfast.

Provenance and peer review Not commissioned; externally peer reviewed.

Data sharing statement The raw data for this research consist of audiorecordings of narrative interviews and audio diaries. The principal investigator (Professor Lynn V Monrouxe) has access to this specific data set, including audiorecordings of interviews and interview transcripts, in addition to participant contact details and signed consent forms. All authors have access to anonymised data from this set. All data are stored securely on password-protected and encrypted computers. Participants have not given their permission for data sharing outside the research group. Thus, no additional data are available.

Open access This is an open access article distributed in accordance with the Creative Commons Attribution Non Commercial (CC BY-NC 4.0) license, which permits others to distribute, remix, adapt, build upon this work non-commercially, and license their derivative works on different terms, provided the original work is properly cited, appropriate credit is given, any changes made indicated, and the use is non-commercial. See: http://creativecommons.org/licenses/by-nc/4.0/.

\section{REFERENCES}

1. Royal College of General Practitioners. The 2022 GP: a vision for general practice in the future NHS. Royal College of General Practitioners London, 2013 http://test.bathandnortheastsome rsetccg.nhs.uk/assets/uploads/2016/01/the-2022-gp-a-vision-forgeneral-practice-in-the-future-nhs.pdf Accessed 15th Aug 2018.

2. van Oostrom SH, Gijsen R, Stirbu I, et al. Time trends in prevalence of chronic diseases and multimorbidity not only due to aging: data from general practices and health surveys. PLoS One 2016;11:e0160264.

3. Khairy P, Van Hare GF, Balaji S, et al. PACES/HRS expert consensus statement on the recognition and management of arrhythmias in adult congenital heart disease. Can J Cardiol 2014;30:e1-e63.

4. Piepoli MF, Hoes AW, Agewall S, et al. 2016 European Guidelines on cardiovascular disease prevention in clinical practice. Atherosclerosis 2016;252:207-74.

5. Windsor J, Searle J, Hanney R, et al. Building a sustainable clinical academic workforce to meet the future healthcare needs of Australia and New Zealand: report from the first summit meeting. Intern Med J 2015;45:965-71.

6. Greenaway D. Shape of training: Securing the future of excellent patient care: Final report of the independent review. 2013. http:// www.shapeoftraining.co.uk/static/documents/content/Shape_of_ training_FINAL_Report.pdf_53977887.pdf

7. UK Shape of Training Steering Group (UKSTSG). Report from the UK Shape of Training Steering Group. Edinburgh, 2017. https://www. shapeoftraining.co.uk/static/documents/content/Shape_of_Training Final_SCT0417353814.pdf

8. Pershing S, Fuchs VR. Restructuring medical education to meet current and future health care needs. Acad Med 2013;88:1798-801.

9. Monrouxe L, Bullock A, Cole J, et al. How Prepared are UK Medical Graduates for Practice? Final report from a programme of research commissioned by the General Medical Council: GMC. 2014. https:// www.gmc-uk.org/-/media/about/how-prepared-are-uk-medicalgraduates-for-practice.pdf?la=en\&hash=1797AFD84B58E269D4FA B5E107A99EE93509ED12 (accessed 15 Aug 2018).

10. Monrouxe LV, Grundy L, Mann M, et al. How prepared are UK medical graduates for practice? A rapid review of the literature 20092014. BMJ Open 2017;7:e013656.

11. Jen $\mathrm{MH}$, Bottle A, Majeed A, et al. Early in-hospital mortality following trainee doctors' first day at work. PLoS One 2009;4:e7103.

12. Sharma V, Proctor I, Winstanley A. Mortality in a teaching hospital during junior doctor changeover: a regional and national comparison. Br J Hosp Med 2013;74:167-9.

13. Monrouxe LV, Bullock A, Tseng HM, et al. Association of professional identity, gender, team understanding, anxiety and workplace learning alignment with burnout in junior doctors: a longitudinal cohort study. BMJ Open 2017;7:e017942.

14. General Medical Council. The state of medical education and practice in the UK report: 2014. 2014.http://www.gmc-uk.org/ SOMEP_2014_FINAL.pdf_58751753.pdf 15th Aug 2018

15. Vaughan L, McAlister G, Bell D. 'August is always a nightmare': results of the Royal College of Physicians of Edinburgh and Society of Acute Medicine August transition survey. Clin Med 2011;11:322-6.

16. Miles S, Kellett J, Leinster SJ. Medical graduates' preparedness to practice: a comparison of undergraduate medical school training. BMC Med Educ 2017;17:33.

17. Bleakley A, Brennan N. Does undergraduate curriculum design make a difference to readiness to practice as a junior doctor? Med Teach 2011;33:459-67.

18. Morrow G, Johnson N, Burford B, et al. Preparedness for practice: the perceptions of medical graduates and clinical teams. Med Teach 2012;34:123-35.

19. Burford B, Whittle V, Vance $\mathrm{GH}$. The relationship between medical student learning opportunities and preparedness for practice: a questionnaire study. BMC Med Educ 2014;14:223. 
20. Illing JC, Morrow GM, Rothwell nee Kergon CR, et al. Perceptions of UK medical graduates' preparedness for practice: a multi-centre qualitative study reflecting the importance of learning on the job. BMC Med Educ 2013;13:34.

21. Eva KW, Regehr G. Self-assessment in the health professions: a reformulation and research agenda. Acad Med 2005;80:S46-S54.

22. Schön D. The reflective practitioner: how professionals think in action. London: Temple Smith, 1983.

23. Monrouxe LV, Rees CE. "It's just a clash of cultures": emotional talk within medical students' narratives of professionalism dilemmas. Adv Health Sci Educ Theory Pract 2012;17:671-701.

24. Monrouxe LV. Solicited audio diaries in longitudinal narrative research: a view from inside. Qualitative Research 2009;9:81-103.

25. ATLAS. ti Scientific Software Development GmbH [program], Version 7.

26. Ritchie J, Spencer L. Qualitative Data Analysis for Applied Policy Research. In: Bryman A, ed. Analyzing Qualitative Data. London: Routledge, 1994.

27. Mattick KL, Kaufhold K, Kelly N, et al. Implications of aligning full registration of doctors with medical school graduation: a qualitative study of stakeholder perspectives. BMJ Open 2016;6:e010246.

28. Kostov CE, Rees CE, Gormley GJ, et al. 'I did try and point out about his dignity ': a qualitative narrative study of patients and carers' experiences and expectations of junior doctors. BMJ Open 2018;8:e017738.

29. Rees CE, Bullock A, Mattick K, et al. Using workplace-learning narratives to explore evaluative judgment in action. Boud $D$, ed. Developing Evaluative Judgement in Higher Education: Assessment for Knowing and Producing Quality Work: Taylor \& Francis Ltd in press.

30. Lundin RM, Bashir K, Bullock A, et al. "I'd been like freaking out the whole night": exploring emotion regulation based on junior doctors narratives. Adv Health Sci Educ Theory Pract 2018;23:7-28.

31. General Medical Council. Outcomes for Graduates (Tomorrow's Doctors). 2015 (15th Aug 2018).

32. O'Connor P, Lydon S, O'Dea A, et al. A longitudinal and multicentre study of burnout and error in Irish junior doctors. Postgrad Med $\mathrm{J}$ 2017;93:660-4.

33. Brown JM, Watmough S, Cherry MG, et al. How well are graduates prepared for practice when measured against the latest GMC recommendations? Br J Hosp Med 2010;71:159-63.

34. Wijnen-Meijer M, Kilminster S, Van Der Schaaf M, et al. The impact of various transitions in the medical education continuum on perceived readiness of trainees to be entrusted with professional tasks. Med Teach 2012;34:929-35.

35. McGettigan P, McKendree J, Reed N, et al. Identifying attributes required by Foundation Year 1 doctors in multidisciplinary teams: a tool for performance evaluation. BMJ Qual Saf 2013;22:225-32.

36. Lewis PJ, Tully MP. Uncomfortable prescribing decisions in hospitals: the impact of teamwork. J R Soc Med 2009;102:481-8.

37. Brennan N, Corrigan O, Allard J, et al. The transition from medical student to junior doctor: today's experiences of Tomorrow's Doctors. Med Educ 2010;44:449-58.

38. Goldacre MJ, Taylor K, Lambert TW. Views of junior doctors about whether their medical school prepared them well for work: questionnaire surveys. BMC Med Educ 2010;10:78.

39. Tallentire VR, Smith SE, Wylde K, et al. Are medical graduates ready to face the challenges of Foundation training? Postgrad Med $\mathrm{J}$ 2011;87:590-5.
40. Goldacre MJ, Lambert TW, Svirko E. Foundation doctors' views on whether their medical school prepared them well for work: UK graduates of 2008 and 2009. Postgrad Med J 2014;90.

41. Matheson C, Matheson D. How well prepared are medical students for their first year as doctors? The views of consultants and specialist registrars in two teaching hospitals. Postgrad Med $J$ 2009;85:582-9.

42. Watmough S, Cherry MG, O'sullivan H. A comparison of selfperceived competencies of traditional and reformed curriculum graduates 6 years after graduation. Med Teach 2012;34:562-8.

43. Eraut M. Informal learning in the workplace. Studies in Continuing Education 2004;26:247-73.

44. Rees CE, Crampton P, Kent F, et al. Understanding students' and clinicians' experiences of informal interprofessional workplace learning: an Australian qualitative study. BMJ Open 2018;8:e021238.

45. Carling J. Are graduate doctors adequately prepared to manage acutely unwell patients? Clin Teach 2010;7:102-5.

46. Cleland JA, Ross S, Miller SC, et al. "There is a chain of Chinese whispers": empirical data support the call to formally teach handover to prequalification doctors. Qual Saf Health Care 2009;18:267-71.

47. Fox FE, Doran NJ, Rodham KJ, et al. Junior doctors' experiences of personal illness: a qualitative study. Med Educ 2011;45:1251-61.

48. Bertels J, Almoudaris AM, Cortoos PJ, et al. Feedback on prescribing errors to junior doctors: exploring views, problems and preferred methods. Int J Clin Pharm 2013;35:332-8.

49. Cave J, Woolf $\mathrm{K}$, Jones A, et al. Easing the transition from student to doctor: how can medical schools help prepare their graduates for starting work? Med Teach 2009;31:403-8.

50. Davis D, MacLullich A. Understanding barriers to delirium care: a multicentre survey of knowledge and attitudes amongst UK junior doctors. Age Ageing 2009;38:559-63.

51. Dawson AG, Bruce SA, Heys SD, et al. Student views on the introduction of anatomy teaching packages into clinical attachments. Clin Anat 2009;22:267-72.

52. George JT, Warriner D, McGrane DJ, et al. Lack of confidence among trainee doctors in the management of diabetes: the Trainees Own Perception of Delivery of Care (TOPDOC) Diabetes Study. QJM 2011;104:761-6.

53. Linklater GT. Educational needs of foundation doctors caring for dying patients. J R Coll Physicians Edinb 2010;40:13-18.

54. Richardson L, Ea SP. Writing: a method of inquiry. In: Denzin NK, Lincoln YS, eds. The Sage handbook of qualitative research. Thousand Oaks, CA: Sage Publications Ltd, 2005:959-78.

55. Kassim SS, McGowan Y, McGee H, et al. Prepared to practice? Perception of career preparation and guidance of recent medical graduates at two campuses of a transnational medical school: a cross-sectional study. BMC Med Educ 2016;16:56.

56. Sheu L, Kogan JR, Hauer KE. How supervisor experience influences trust, supervision, and trainee learning: a qualitative study. Acad Med 2017;92:1320-7.

57. General Medical Council. Clinical placements for medical students: advice supplementary to Tomorrow's Doctors (2009). London: General Medical Council, 2011.

58. Proctor B. Supervision: a co operative exercise in accountability. In: Marken M, Payne M, eds. Enabling and Ensuring. Leicester: Leicester National Youth Bureau and Council for Education and Training in Youth and Community Work, 1986:21-3. 